to set up quantitative standards of composition, to lay down detailed specifications for what may appear on the label or in an advertisement. That is why it is forbidden any longer to sell a "digestive" biscuit, since the digestibility of all biscuits may be assumed, while Bristol Cream, deficient as it is in butter-fat content, retained its label by special dispensation. Only approved colours, preservatives, flavours and other substances added to improve the texture or retain the moisture-all so properly described as "additives"-can today be added. And behind all this stands the scientist who alone possesses the skill to determine whether the law has been obeyed and the rules kept.

Refinements of the present rules are coming as we watch. Already shopkeepers are being required on pain of prosecution to sell some foods before a predetermined date although so far it is not actionable to be caught eating stale bread. And the Food Standards Committee, recognising that beans are different from meat, are proposing that, should a manufacturer fabricate beans into the semblance and texture of meat, he should mix with them a due proportion of the amino acid methionine

Clearly, it is important to insure that food is wholesome, uncontaminated by toxic substances and not misleadingly labelled. The question to be asked now, after a hundred years spent applying more and more scientific ingenuity, is whether the means have been justified by the ends that have been attained.

Have increasing health and happiness followed each addition of sophisticated control and regulation? Do labels bearing lists of "additives" in small print contribute to the contentment of those who eat baked beans, fish paste and tubs of margarine? The unification of standards of food composition and of the analytical procedure needed to verify their maintenance, first within the country as a whole, next throughout the European Economic Community and finally, as soon as can be done, across the whole world, is already in hand. A council of wise men such as that set up by James I to prepare an English version of the Bible is well advanced in its work to prepare the Codex Alimentarius, the world gospel of food composition.

Although it is right and proper for all these great men, distinguished in science and prominent in government and administration, nationally, internationally and world-wide, to review the progress that has been made, the end of a century of effort to apply science to the control of food quality and safety is a good time to stop, just as Professor Newbould has done, not merely to see how nearly the targetof perfect quality and absolute safety - has been approached but to consider whether there is perhaps a different target to be shot at. Do people fuss and worry about the safety and wholesomeness of their food in spite of the devoted efforts of the Food Standards Committee, the Food Additives and Contaminants Committee and the Labelling of Food Regulations or because of them? Is the health of the community safeguarded more effectively by forbidding the use of cyclamates on the basis of subtle circumstantial evidence based on animal experimentation on which scientific opinions is, to say the least, divided or, let us say, by making cyclamates compulsory in order to minimise the consumption of sugar which is known to be harmful? There are other questions, likewise never asked, of which the biggest is: since, of all the contributing factors, lack of money is the most potent cause of poor diet, should we not measure the cost of the vitamin enrichment of bread and margarine, of analysis for the presence of required ingredients and the absence of proscribed ones, of the listing of components on labels, of the wrapping and packing of this and the discarding and disposal of that, to try to strike a balance between the benefits all these measures bring and the price that has to be paid for them.

These, however, are technical questions and, whatever shortcomings there still may be and whatever questions still remain unanswered, the distinguished people who set up the standards, do the analyses, measure the risks and add the vitamins are above all competent in their fields. The philosophy behind their century of forward march is, however, that of science and, as it sometimes seems, of a science that is assumed to be capable of ensuring that absolute safety and perfect purity-standards to which in the end all the world's food must conform. In the century ahead there is room for a new idea.

Obviously, our food must be fit to eat and we need to apply scientific understanding to keep it so. But, since there is no such thing as absolute safety, any more than there will ever be complete knowledge, there is room in the next century for those who invent the food laws to allow some of the people some of the time to eat at their own risk. Perhaps if the scientific advisers and governors let it thus be known that British scientists know that they do not know everything nor ever will and that they are not able to avert every "Act of God", the ordinary citizen would be less inclined to blame the government for every misfortune.

Magnus Pyke

\section{One step from chemical automatons}

\author{
by Akiyoshi Wada
}

By anyone's standards, the revelation of the molecular mechanism of life must be considered one of the highlights of the history of natural science. To make this revelation more meaningful and beneficial to mankind, those engaged in research on biological molecules must begin to think of possible practical applications of the molecular mechanism of life. For this purpose, a committee was formed in Japan about a year ago to examine and explore industrial applications of biological molecules with special emphasis on enzymes and other functional biopolymers. This is one of the projects under the auspices of the Council of Science and Technology in Japan for the promotion of life science. The committee is still carrying out its work, but wishes to present an interim report on the general image of what these applications might be, in the hope that it will stimulate a response from those who are engaged in biopolymer research.

A LIVING body is a molecular machine whose parts are molecules; machines using molecules as functional parts are obviously far more compact than present man-made machines. We already know the functions of individual parts, which make up complicated yet ordered chemical circuits. We also know how higher order structures are constructed and regulated, how energy is converted from one form to another, and how information is transmitted in these chemical circuits. The knowledge of these functions and mechanisms serves as the basis for the next stage of our project: the development of a chemical automaton with highly developed self-contained chemical circuits.

Rather like an electronic computer, this automaton would convert input into output; in the automaton's case, however, input and output would be molecules. An electronic computer is made up of hardware and software; a chemical automaton needs an additional component, a chemical reaction 
system which might be called 'wetware'. The functional molecular units of a chemical automaton serve for:

- Reaction.

- Regulation.

- Information storage.

- Material transfer.

- Separation of materials.

- Transport of energy.

- Conversion of energy.

- Detection of parameters at each of the reaction stages.

The ultimate automaton is likely to be what might be called a 'synthetic living body' which consists mainly of wetware and software. But, for now we should concentrate on developing automatons which also include hardware such as measuring devices, computers and energy sources. For this purpose we must first develop the following topics:

- Stable and specific catalysis.

- Specific selective membranes.

- Reaction control systems including measuring devices.

- Chemical circuit theories.

- Energy transducers.

Topics in basic research which need to be studied and therefore to be supported for the development of the above items are:

- Biopolymers, in particular the structure and functions of enzymes.
- Molecular mechanisms of specific reactivity and its regulation.

- Organic reactions in aqueous and neutral conditions (without strong acids or bases).

- Synthesis of polymers of determined sequence.

- Stabilisation and immobilisation of natural enzymes for easy use.

- Specific permeable membranes.

- Mechanism of energy conversion in biological systems.

- Stability of chemical reactions in relation to spatial and temporal chemical oscillations.

- Development of highly sophisticated measurement techniques in physics and chemistry needed for the aforementioned research topics. (For example, we can cite the most upto-date electronic and mechanical devices and computers.)

Many obstacles lie in the way of the realisation of chemical automatons. They may seem insurmountable, but in comparison with dreaming of flying 100 years ago, or speculating on high speed computers 50 years ago, chemical automatons are only a step away. In any event, nature provides chemical automatons as living bodies, and the principle behind their working mechanism is fairly well understood. Thus, the obstacles are indeed surmountable, and efforts made in overcoming these obstacles are well worth exerting, when we think of the beneficial effects of chemical automatons on society.

Some of the direct effects would come from a new form of chemical industry, operating at normal temperature and pressure in the state of aqueous solution, requiring minimal energy and producing no harmful byproducts. Other benefits would be flow production of complex chemicals which does not disturb the environment, and the possibility of the full use of substances abundantly available in nature, such as air, water and carbon dioxide.

Indirectly, chemical automatons would affect both basic and applied sciences covering a wide range of fields such as biophysics, molecular biology, biochemistry, polymer chemistry, the textile industry and the pharmaceutical industry.

In the advanced nations, including Japan, the potential for the development of chemical automatons is great. Barriers do, however, exist for such people to switch their specialities to life science. The automaton project straddles over many academic disciplines, and it is hoped that it could serve to trigger meaningful interdisciplinary research centring on the molecular life sciences.

\section{international news}

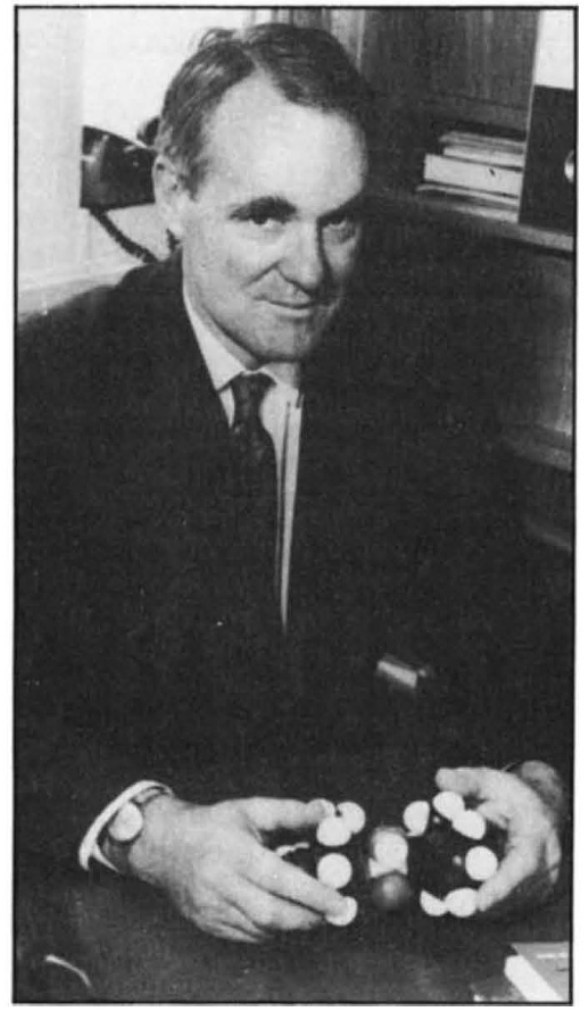

in the past week, Nobel Prizes for medicine, chemistry and physics, at $£ 69,000$ tax-free a time, have been shared by eight European and US scientists. The prize for medicine was shared by Renato Dulbecco, a 61-yearold Italian-born American now working at the Imperial Cancer Research Fund, London, and two of his former pupils-David Baltimore, aged 37, of the Massachusetts Institute of Technology, and Howard Temin (40), of is the University of Wisconsin.

Baltimore was Dulbecco's student at the Salk Institute for Biological Studies, and Temin studied under him at the California Institute of Technology. They receive their prize for their work on the circumstances and effects which cause cancer. Dr Dulbecco's work has been on the mechanics by which animal viruses insert their own genetic material (DNA) into that of

animal cells. This can enable them to convert the cell into a virus factory, but it can also transform the cell into a cancerous state.

Dr Temin and Dr Baltimore share the credit for an outstanding discovery about RNA tumour viruses. RNA usually acts as the messenger molecule by which the genetic instructions of body cells are translated into proteins. Dr Temin and Dr Baltimore were convinced that RNA tumour viruses must be able to reproduce themselves in a DNA form to enter the cell's genetic machinery. Ten years after Dr Temin first predicted it, both men almost simultaneously found the enzyme that enables them to do it. The enzyme enables the virus to make DNA from RNA.

The discovery stood conventional biology on its head because it reversed the genetic process by which DNA makes RNA and RNA then makes protein.

Many RNA viruses are involved in animal cancers and it is believed that some human cancers may be caused in the same way. Work with these viruses 